\title{
Marcelo Rougier y Juan Odisio, Argentina será industrial o no cumplirá sus destinos. Las ideas sobre el desarrollo nacional (1914-1980), Buenos Aires, Imago Mundi, 2018, 496 pp.
}

\author{
Guillermo Vitelli ${ }^{1}$ * D 0000-0002-1466-6837 \\ ${ }^{1}$ Consejo Nacional de Investigaciones Científicas y Técnicas, Buenos Aires, Argentina. \\ *Correspondencia: gmovitelli@gmail.com
}

El título del libro de Marcelo Rougier y Juan Odisio constituye una toma de posición militante sobre la necesidad de inducir y sostener el desarrollo industrial en Argentina. Del texto surge que esa es la base central para estructurar una nación viable posibilitando un bienestar creciente. Ese no ha sido en la historia económica de Argentina un precepto siempre aceptado. Por el contrario, la nación ha transitado en su historia reciente dos desindustrializaciones provocadas desde políticas económicas internas, las de la segunda mitad de la década de 1970 y la de la década de 1990. Hacia 2018 estaría transitando la tercera merma de bases manufactureras, también promovida desde concepciones políticas de los grupos gobernantes y gestada por instrumentos económicos locales, a pesar que ese precepto de sostener la industrialización como eje del crecimiento fuera formulado hace más de 100 años por Manuel Ugarte y que, desde entonces, numerosos intelectuales y actores de la vida pública argentina desarrollaron ideas y propuestas conceptualmente válidas sobre las ventajas y los modos de implantar la industrialización. Las consecuencias de esas desindustrializaciones fueron aumentos de la marginalidad, del desempleo y de la pobreza. Además, consolidaron distribuciones regresivas de los ingresos de difícil reversión. Pero fundamentalmente conformaron pérdidas de acumulaciones pasadas de capital y la destrucción de organizaciones productivas y de capacidades en la mano de obra.

Rougier y Odisio estructuran, ordenando cronológicamente las ideas sobre la industrialización, gestadas y empleadas en Argentina, una historia temática que aporta al conocimiento de la historia global y que permite pensar y diseñar políticas económicas de largo plazo. Es el primer libro que compila las concepciones que se formularon para inducir el desarrollo de la manufactura en Argentina, empleando una segmentación temporal muy sugestiva pero no menos válida: desde 1980. Ese fue, sin duda, el tramo que contuvo el mayor desarrollo de ideas sobre la necesidad de la industrialización como modo de concretar un crecimiento sostenido en Argentina. Fue también

Esta obra está protegida bajo una Licencia Creative Commons Atribución-NoComercial 4.0 Internacional

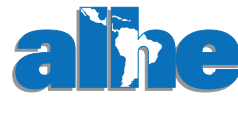

http://alhe.mora.edu.mx

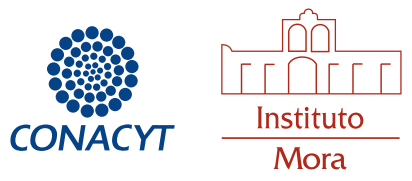


el tramo de tiempo de mayor expansión de las bases manufactureras, que concluyó, según los autores, con el fin del consenso industrialista, formulado desde las estructuras de gobierno. Ese corte temporal es coincidente con la primera desindustrialización inducida desde las esferas gubernamentales y de poder, seguida por otra en corto tiempo, la de los años noventa, y por el tránsito de una tercera desindustrialización premeditada. Cuatro décadas de desindustrialización que coincidieron con los mayores rezagos de la economía argentina frente al derrotero de las naciones más industrializadas y de numerosos vecinos.

La temática que sistematizaron Rougier y Odisio describe el optimismo que existió acerca de los resultados factibles que induce la industrialización, mostrando que se promovía acertadamente "la creación de lo posible" a pesar que, en algún momento en el pasado, durante la segunda mitad del siglo xIx, se afirmaba que con el desarrollo de la manufactura se crearían industrias artificiales, empleando el argumento que el país carecía de hierro y carbón. Quizá aquella interpretación desmotivadora conformó una de las raíces que sustentaron las críticas posteriores a la formación de manufacturas locales. Pero luego se comprendió la necesidad de industrializar para "cumplir los destinos" venturosos que se avizoraban para Argentina a comienzos del siglo xix.

Las ideas y los promotores no fueron pocas. Entre los pensamientos pioneros se encontraron los de Alejandro Bunge en su Revista de Economía Argentina, sustentando la creación de instituciones formadoras de políticas como la Unión Industrial Argentina y abriendo paso a un consenso que luego de los años posteriores a 1976 se quebraría, el de la intervención estatal como basamento necesario de la industrialización.

Luego en el libro transitan las ideas incorporadas por Federico Pinedo en su plan, que coincidió con el desarrollo de la industria liviana formado durante los años de la segunda guerra mundial, como respuesta ineludible al cierre de los mercados mundiales, y que sustentaron la necesidad de implantar posteriormente la industrialización pesada, promovida desde las teorías del desarrollo vigentes entonces, como las de Hirschman, Prebisch, Rosenstein Rodan y otros, y que en Argentina se encarnaron en el desarrollismo, corporizado políticamente en el eje programático que lideraron a finales de los años cincuenta Arturo Frondizi y Rogelio Frigerio y que en Brasil caracterizó y guió al gobierno de Juscelino Kubitschek. Esas coincidencias temporales en las ideas económicas vigentes en varias naciones y también de programas de política económica surgen notoriamente desde la sistematización que Rougier y Odisio realizan acerca de los modos de gestar la industrialización durante los años posteriores al comienzo de la segunda guerra. En esos años posteriores a la segunda guerra el optimismo de lo factible estaba instalado en las concepciones que impulsaban entonces la industrialización y que conformaron tiempos donde se vislumbraba la posibilidad de conformar un país que, a su base agropecuaria ya instalada y en expansión, se agregara el sustento industrial, no diferente del derrotero seguido por Australia, Brasil y Canadá.

Una de las restricciones económicas básicas de Argentina ha sido, reiteradamente, la externa: su dificultad para lograr las divisas necesarias para instalar y sostener el desarrollo productivo, induciendo mayor bienestar a la población. Desde las ideas de la industrialización, Rougier y Odisio presentan el ingreso del capital externo en la manufactura como uno de los instrumentos promovidos para superar esa restricción, derivando de allí, correctamente, los años que caracterizan como dorados en el desarrollo industrial, los de 1969.

En el plano de la restricción externa rescatan un concepto fundante del pensamiento de Raúl Prebisch y que no necesariamente era absolutamente pro industrializador: el de generar un industrialismo "moderado" basado en la relación entre precios internos y externos. Uno de los temas asociados a la industrialización se encuentra en la ecuación formada entre los precios de exporta- 
ción agropecuarios, los costos de producción de bienes manufacturados internamente y los precios de importación de bienes industriales. Prebisch sustentaba la necesidad de industrialización cuando esa ecuación motivaba el drenaje de divisas, agudizando la restricción esencial de la economía argentina. Su visión, que puede ser considerada cortoplacista, motivaba que la promoción de la industrialización dependiera de los vaivenes de la relación cuantitativa entre esos tres precios, marginando el armado de una política de industrialización de largo plazo, a pesar que el pensamiento de la Comisión Económica para América Latina y el Caribe fuera, en los años dorados, predominantemente industrialista.

El corte temporal que formulan Rougier y Odisio como cierre de su estudio, el de 1980, permite abrir una pregunta inversa a la que da base al libro: ¿qué ideas e intereses sustentaron y subyacen en las propuestas de desindustrialización? Son numerosas las líneas que describen en el libro acerca de las concepciones no promotoras de la industrialización. Su sistematización no es intrascendente porque permite comprender las bases ideológicas y las concepciones teóricas que dieron y dan sustento a tiempos desindustrializadores.

Entre los múltiples valores del libro de Rougier y Odisio se encuentra el énfasis de la necesidad de conformar capitales intelectuales, sustentando y divulgando la idea de industrializar como un destino correcto de Argentina. También rescatan el papel institucional en el desarrollo industrial, corporizado en organismos como la Unión Industrial Argentina, la Confederación General Económica, y de instituciones estatales como el Inti y que en propuestas desindustrializadoras tienden también a ser minimizados. Como modo de conformar capitales intelectuales, acertadamente reivindican como esenciales seminarios como los que se realizaron en los años sesenta en el Instituto Torcuato Di Tella analizando los modos de desarrollo de la industrialización y sus vínculos con las cuentas macroeconómicas, gestando ideas e ideologías promotoras del implante de las manufacturas. En realidad, la acumulación de pensamientos, investigaciones y propuestas de política acerca de los modos posibles de desarrollo industrial conforma, lo que los autores acertadamente caracterizan como la formación de ese capital intelectual, esencial para la definición y permanencia de políticas de Estado. En Argentina el pensamiento de derecha, de raíz monetarista y anti estatal, ha procurado desestimular la instalación de bases industriales conformando un acervo intelectual e ideológico que intentó desvalorizar la formación de bases industriales, aportando a las desindustrializaciones que ha transitado Argentina.

El libro aportará notoriamente al rescate del capital intelectual perdido, facilitará las discusiones acerca de los modos de desarrollo industrial y también apoyará la formación de estudiantes que asuman la idea de la industrialización como una de las bases de sustento de mayor bienestar para la población y de crecientes posibilidades laborales.

La industria es, sin duda, una derivación natural de la educación: todo alumno de ingeniería, en cualquiera de sus ramas, biología, química y de numerosas carreras más, es un potencial empresario. El libro de Rougier y Odisio podrá ayudar a instalar nuevamente el optimismo que alguna vez predominó en Argentina en el pensamiento económico y en las propuestas de política económica rescatando la necesidad de revitalizar ideas fundantes de la industrialización, marginando planteos monotemáticos que asocian a los "males" sólo con déficits fiscales o la necesidad de contener procesos inflacionarios abriendo la importación de bienes para asociar los precios internos a los externos.

El libro será de extrema utilidad para la formación intelectual en las universidades y para posibilitar, nuevamente, la discusión acerca del país posible. 